\title{
Implementation Challenges of National Language Policy in Nigeria: The Roles of the Indigenous Languages
}

\author{
Francis Abah. Owojecho \\ Department of English Language, Institute of Education, \\ University of Abuja \\ fowojecho@gmail.com
}

DOI: https://doi.org/10.36892/ijlls.v2i1.183

\begin{tabular}{|c|c|}
\hline $\begin{array}{l}\text { Received: } \\
\text { 24/01/2020 }\end{array}$ & $\begin{array}{c}\text { Abstract } \\
\text { The administration and maintenance of linguistic plurality and }\end{array}$ \\
\hline $\begin{array}{l}\text { Accepted: } \\
31 / 03 / 2020\end{array}$ & $\begin{array}{l}\text { multilingualism in Nigeria seem to come with many challenges, given a } \\
\text { setting within which English is still being assigned dominant functional } \\
\text { roles. Language policy which is a deliberate effort to mandate specific }\end{array}$ \\
\hline $\begin{array}{l}\text { Keywords: } \\
\text { Language Policy, } \\
\text { Language Planning, } \\
\text { Multilingualism, } \\
\text { Indigenous Languages, } \\
\text { Minority Languages }\end{array}$ & $\begin{array}{l}\text { language behaviours in particular contexts is characterized by many } \\
\text { obvious implementation defects in Nigeria. Such defects revolve around lack } \\
\text { of decisive policy guidelines being implemented about language } \\
\text { development and allocation, language use, language rights, and a host of } \\
\text { other important issues. This paper examines the detrimental effects that poor } \\
\text { implementation of national language policy initiatives in Nigeria has had on } \\
\text { the development and survival of indigenous languages in the immediate past. } \\
\text { It reveals the unhealthy attitude of many Nigerians elite groups towards the } \\
\text { sustainability of indigenous languages, the inability of successive } \\
\text { government to select a single viable national language from the indigenous } \\
\text { languages, non-codification of many minority languages, and inadequate } \\
\text { definition of roles for indigenous languages in governance. The survey } \\
\text { method which is aimed at generating and analysing empirical data on the } \\
\text { subject matter of the "implementation challenges associated with current } \\
\text { National Language Policy guidelines, vis-à-vis the multi-dimensional } \\
\text { functions of English"' in the current Nigerian sociolinguistic setting was } \\
\text { used. } \\
\text { The study found that the lack of adequate implementation of the language } \\
\text { policy initiatives has given prominence to English which is consequently } \\
\text { endangering the indigenous languages in Nigeria. }\end{array}$ \\
\hline
\end{tabular}

\section{INTRODUCTION}

The underlying dynamics of Nigeria's dense multilingualism and multiculturalism constitutes serious challenges to past efforts to select a single viable national language. This challenge has continued to provide English with the space to remain a predominant factor in the Nigerian sociolinguistic setting today. This is demonstrated in the multipurpose usage of English as the language of education, language of governance and administration, language of legal/judicial administration, language of legislation, language of journalism/the press, language of advertisement, language of research, lingua franca of the elite, language of sports commentaries and the language of religious worship among new generation churches side- 
lining the indigenous languages. Previous researches have been carried out to address the challenges of the crowded multilingualism, inconsistent language policy and implantation, none codification of the indigenous language, inability of the government to pick one of the indigenous languages as a national language and the limited roles of the indigenous languages. Ajepe and Ademowo (2016) carried out a research on the dominant role of English language and they found that the dominance of the English language in Nigeria has naturally relegated the use of the indigenous languages. The research of Ibrahim and Guandu (2016) on language policy on Education in Nigeria reviewed that as against the indigenous languages, the future of English language in Nigeria is very bright because of its roles. Their research also found that multilingualism and poor language planning and implementation pose a lot of challenges to multilingual education. In relation to the previous researches, this study is aimed at exposing the implementation challenges associated with current National Language Policy guidelines, vis-à-vis the multi-dimensional functions of English that have become an impediment to the growth of the indigenous languages.

Ajepe and Ademowo (2016, p. 1) have asserted that "the blind glorification of English language by the elites as well as the defective National Policy on Language has conspired to undermine the local languages and rob them of their importance in national development drive". They went further to say that the dominance of English is not inflicted by the indispensability of the language, but by the fact that indigenous have been forced to take the back seat today in the country instead of being actively used to promote indigenous cultural values following the end of British colonial rule. It is necessary to attempt to unravel what led to the progressive decline in the social value associated with these languages in present day Nigeria. It is a sad commentary that if nothing is done quickly to begin the implementation of the language policy, the indigenous languages will not only be endangered as many are already, but also go into extinction due to lack of comprehensive language policy and its implementation as a deliberate exercise in Nigeria.

This research was therefore informed by the following questions: Are Nigerians aware of the National Language Policy? Is the Policy implementable considering the roles English language is playing? What are the key challenges in implementing the language policy in Nigeria and how do the challenges affect the indigenous language? The research aimed to answer these research questions within the framework of descriptive, survey-based study.

\section{HISTORICAL ANTECEDENTS OF INDIGENOUS LANGUAGES IN NIGERIA}

Before Nigeria came in contact with the colonialists, it existed as a sprawling territory of diverse ethnic groups, with each group having distinct (and to some extent overlapping) historical, linguistic, cultural patterns expressed in traditional socio-political, educational and religious systems (Ajayi and Smith 1964, Dike 1956, Enoch 1996, as cited in Ogunmodimu, 2015). The distinct languages were used primarily in various regions and localities for communication and trade.

When the English language was introduced in Nigeria over a century ago, that is, at the beginning of the 19th century when the British colonialists came as missionaries, Nigeria was already a multilingual setting and till today it is still linguistically heterogeneous. English met about 400 indigenous Nigerian languages most of which are still in existence (Oluga and Babalola, 2012). Ajepe and Ademowo (2016) hold that in the course of colonisation, Nigerian indigenous languages progressively came into active contact with English, the language of the colonialists. Within the context of this language contact, English acquired predominant influence by virtue of being main medium used for colonial administration, European missionary evangelism and education. Much later, at the attainment of political independence, the language was bequeathed to Nigeria as part of British colonial legacy. 
According to Ajepe and Ademowo (2016), it was unfortunate that even after several decades of attaining political independence, Nigeria has still not been able to fashion out durable language policies that would create and maintain sustainable functions for indigenous languages in the country. Unfortunately, even today, English (a product of British colonial heritage) still enjoys primacy through the cross-ethnic function that it performs in the sociocultural milieu of the country.

3. THE DYNAMICS OF LANGUAGE POLICY AND IMPLEMENTATION IN

\section{NIGERIA}

The advocacy for a workable language policy that will give all classes of language due recognition can never be understated due to the complex linguistic situation in Nigeria. The absence of a sustainable national language policy has continued to give English considerable (and arguably undeserved) prestige, at the expense of the numerous indigenous languages in the country. It is in this regard that one is somewhat persuaded by the sentiments expressed in Oluwole (2003) to the effect that language planning as an organized and systematic pursuit of solutions to language problems has remained largely peripheral to the mainstream of Nigeria national planning.

Romaine (2003) defines language planning and policy as the attempt to manage linguistic and cultural contacts and potential conflicts resulting from managing or mismanaging multilingualism within the framework of agencies of the modern nation-state. Crystal 1990 (as cited in Salisu and Dollah, 2015) further suggests that language policy should be understood as a systematic attempt to resolve the communication problems of a community by studying the various dialects it uses and developing a viable policy concerning the use of such language varieties. This means that the primary purpose of language policy is to first identify all available languages and assign functions to them for the purpose of solving communication problems. In the specific case of Nigeria which exhibits a multiplicity of languages, Ajepe and Ademowo (2016) acknowledges that the Nigerian national language policy is embedded in a document of the Federal Government of Nigeria (National Policy on Education, 2013) which contains statutory guidelines regarding the official use of different languages in the country. This policy document has attempted to capture the importance of language to national development, as a means of promoting social interaction and national cohesion, as well as preserving the nation's rich cultural heritage. It is however unfortunate that the processes and procedures for its implementation have not been diligently executed till date.

Nigeria's language policy document referenced above emerged out of national concerns such as the development of a viable National Policy on Education and the drafting of the 1979 democratic Constitution for the country, after a prolonged period of military administration which failed to provide such foundational policy documents and guidelines. Since the initial attempts at drafting and implementing the major guidelines contained in the National Policy of Education in 1981, succeeding revisions of this document in succeeding years have not succeeded in improving upon the recognition and prominence given to the three major languages - Hausa, Igbo and Yoruba, to the obvious neglect of the over five hundred minority languages in Nigeria, as estimated by Ogunmodimu (2015). These indigenous languages have been stratified along the lines of being either 'majority' or 'minority', based on the numerical size of speakers. This demography-based system of classification has inherent political implications, as it essentially visualizes most minority-status languages as occupying marginal positions in the socio-political dynamics of the country. Ogunmodimu (2015, p. 156) has gone further to remark as follows: "Nigeria is now firmly defined along a linguistic line of major languages and minority languages". The predominant recognition given to the three languagesHausa, Igbo and Yoruba- within the context of Nigeria's socio-cultural milieu create in the minds of speakers of other minority-status languages obvious feelings of socio-political marginalization and neglect. These feelings are further compounded by the insidious hyping 
and exaltation of the virtues of English over and above any other Nigerian language as the predominant medium for official administration and education, irrespective of its colonial associations. The political relegation and social marginalization of most minority-status Nigerian languages is firmly rooted in the remnants of British colonial legacies which presented English as the main channel for political and educational administration before 1960 (Ajepe and Ademowo, 2016).

\section{THE CONTINUING DOMINANT ROLE OF ENGLISH IN NIGERIA}

Today in Nigeria, English still serves as the official language performing several roles. According to Akindele \& Adegbite (2005), English is the official language for conducting government business/activities at the federal, state or local government levels. In fact, this is not exclusive of the national assembly. The 1979 constitutional provision for the use of the three major languages in the National Assembly has not been fully implemented till today. The English language is mainly used for the business of the National Assembly.

The role of English in education cannot also be overemphasized. English is predominantly used as the language of education in Nigerian schools. Belkbir (2019) holds that policy makers acknowledge the important role foreign languages, especially English,

play in the professional development of experts and try to present this language at tertiary level. English is used to teach students in upper primary schools (and in many lower and pre-primary schools), in various secondary schools, polytechnics, colleges of education and universities. It is used to write textbooks, lecture notes and other instructional materials as well as tests and examinations with the exception of those in other languages (Oluga and Babalola, 2012). The National Policy on Education (NPF) which states that the medium of instruction in pre-primary schools shall be the language of immediate community is disrespected in this regard. That is why Igbojinwaekwu and Nneji (2012) asserts that despite the policy of using the language of the immediate environment as medium of instruction in the first three years in the primary school, as contained in NPE (2013), no reliable records exist to show that any privately-owned, state-owned or Federal-owned schools are implementing these policy guidelines. In response to this claim, Dorgu and Igbojinwaekwu (2016) opine that one likely reason is that using mother tongue or language of the environment to teach entails much more than knowing how to speak the language. However, such teachers are often not properly equipped with adequate teaching methodologies and other teaching resources to make the policy implementable. Inadequacies are also observable at various levels of the educational system which makes it expedient, if not obligatory, for educational scholars and text book writers to document and disseminate results of academic research through the medium of English. English also remains the major language used for conduct of proceedings at most national and international seminars and conferences in Nigeria (Oluga, Adewusi, Babalola \& Oyediran, 2002; Danladi, 2013).

In the mass media domain, English has also increasingly forced indigenous languages, even the so-called Nigeria majors, into relative obscurity, within the broader competition for audience in the globalized world of the internet. Not surprisingly, the activities of the media in Nigeria are largely dictated by individual proficiency in English which is, in turn, conditioned by prevailing social attitudes in contemporary Nigerian society. Even in situations where public enlightenment programmes can be broadcast through the medium of indigenous languages, such programmes hardly enjoy widespread viewership on television and listenership on radio, as compared to the broad audience accorded to English programming. The prominence given to English in Nigeria, as highlighted above, is traceable to the longstanding economic and political influence of Britain and the USA, two of the world's leading technological nations. The lackadaisical attitude of a large segment of Nigerian elites, towards 
the promotion and sustenance of indigenous languages, is lamented in Abioye (2010: p. 99) in the following terms:

"Government has consistently exhibited lack of political commitment by paying lip service to its policies rather than actively encouraging and backing the implementation of these. Also, misplaced priorities have seriously affected education in Nigeria as government spends extravagantly on sports and politics whereas projects and policies are poorly implemented/completed, sometimes diverted, inadequately monitored or even abandoned and subsequently forgotten. Indeed, in most cases, educational policies are sometimes personalized and used in scoring cheap political goals or in settling scores".

This inability of the Nigerian government to enforce the implementation of the policy has greatly given the English language a leeway to flourish.

\section{THE AMBIVALENT ATTITUDES OF NIGERIANS TOWARDS \\ INDIGENOUS LANGUAGES}

There is no doubt that either the progress or decline in fortunes of any human language depends largely on the attitude that its native speakers have towards its continued survival at any point in time. An endangered language is technically defined and understood as one that stands the risk of going into eventual extinction if not accorded sufficient protection. On the other hand, a language becomes dead or extinct when it has lost all of its surviving native speakers and has not been transmitted to succeeding generation of speakers before going extinct (Ayakoroma, 2017). Many Nigerian indigenous languages are increasingly facing the serious risk of endangerment because of the non-committal attitude of their native speakers.

In present-day Nigeria, many parents (especially in urban environments) do not encourage the active use of their indigenous languages in carrying out social interactions within the home setting. This may also explain why many Nigerian parents, especially those from elitist socioeconomic backgrounds, are proud to defend their children who are able to speak English, but fail to learn and use the mother tongue(s) of either of their own parents (whether mother or father). It may also be inferred from this common attitude and sociolinguistic practice of some Nigerian parents that they cherish the proficiency of their children in English much more than they value the corresponding competence and familiarity of such children with their parents' mother tongues. In many such instances, it may even be surmised that for many parents English carries so much social prestige that the practice of encouraging their children to learn and speak their own mother tongues would diminish their own perceived social class standing in society.

In order to perhaps help remedy this obvious language-related complex, it is important that speakers of Nigerian languages, particularly those in the minority-status bracket, must make concerted efforts in learning and actively using such languages for interactional purposes in as many social domains as possible. It is in furtherance of this major sociolinguistic goal that Ayakoroma (2017, p. 183) has aptly opined as follows:

"...language remains the foremost medium of propagating ideas, just as it is a veritable tool in facilitating human relations across racial barriers therefore it does not come as a surprise in any way to make concerted efforts in saving the indigenous language from going into extinction".

Given the inherent importance of what is stated above, there are benefits in encouraging the active learning and use of all Nigerian languages, irrespective of whether they are classified as majority or minority. This imperative to learn indigenous languages is particularly applicable to the youth segment of the Nigerian population, on whom the onus rests to ensure the future 
survival and prosperity of these languages, in light of the relentless advancement of globalized language ideologies in today's world.

\section{METHODOLOGY, PROCEDURES AND PRESENTATION OF EMPIRICAL \\ DATA}

The discussion undertaken in this paper is built around and derived from a descriptive, survey-based study which sought to generate and analyse empirical data on the subject matter of the "implementation challenges associated with current National Language Policy guidelines, vis-à-vis the multi-dimensional functions of English" in the Nigerian sociolinguistic milieu. In executing our empirical study of this topic, a special, researcherdesigned, Oral Personal Interview (OPI) instrument was used for collecting relevant data collection. Thirty (30) respondents were purposively sampled from within Abuja metropolis and its immediate environs. The purposive sampling was adopted to provide the specific groups of the target population that match the criteria equal opportunity to participate in the research project; and thereby enhancing the possibility of eliminating or, at least, minimising sampling bias and its impact. Efforts were made to arrive at a representative sample spread across at least twenty (20) states of Nigeria. Similarly, the sample was also confined to respondents, belonging to three (3) professional groups, namely Journalists, Civil Service employees and Secondary School teachers. The motivation for using the above-listed sampling parameters is to ensure that it is possible to capture and represent as many respondents from different language and geographical backgrounds in Nigeria as possible.

In order to preserve the identities of study respondents, the following anonymous labels were assigned to each individual as follows: Journalists - Me1, Me2, Me3, Me4, Me5, Me6, Me7, Me8, Me9, and Me10; Civil Servants - Ad1, Ad2, Ad3, Ad4, Ad5, Ad6, Ad7, Ad8, Ad9 and Ad10; and Teachers - Ed1, Ed2, Ed3, Ed4, Ed5, Ed6, Ed7, Ed8, Ed9 and Ed10.

Data analyses and interpretation were categorised into the perspectives of the three groups of respondents; media managers (journalists), public administrators (civil servants) and school educators (teachers).

\section{Responses from Media Practitioners (Journalists)}

The respondents who were journalists asked a variety of interview questions. On the issue of poly-dimensional functions of English, eight out of ten respondents maintained that they are comfortable with English performing every function in the country. For example, Me3 who was very categorical has this to say:

"Yes of course. Do I have an option? Even when you are not comfortable using English, the system will force you to use it. For example in my station now, If a programme is aired in native language, you loss listenership because not everyone understands that language and even those who understand have no interest. Until government puts plan in place to enforce the learning of native languages, we will continue to be comfortable with English."

As opposed to the popular view, two of the respondents (Me1 and Me7) categorically indicated that they are not comfortable with English and that is why they go extra miles to introduce programmes that are aired and encourage the learning of the indigenous languages. When responding to the question on National Language Policy, all of the respondents in this category attested to be aware of the policy.

Responses from Public Administrators (Civil Servants)

The responses provided by public administrators (civil servants)' to the question on the functions and roles of the English suggested that they are comfortable with English performing several roles. They expressed concern on the multiplicity of indigenous languages. One of the respondents (Ad5) said: 
"We are very comfortable with English o, let me not lie. It is the language we use in correspondences and mailing, though we speak our native languages with those that understand and even pidgin in the office. If we are asked to use any native language as official language of administration, then they have to train us both in speaking and writing. Even though I speak my native language, I cannot write it (laugh...)."

The responses from this set of participants indicate that even though they use English language in official communication, the homogenous indigenous languages and pidgin are being adopted among themselves in the office. Reacting to the question on language policy, many of the participants (Ad2, Ad4, Ad6, Ad7, and Ad8) indicate that they are not aware of any policy. This means that the government and indigenous language advocates still have the duty of creating awareness of the national language policy. They also indicate that not adopting one indigenous language as a national language is one of the major challenges. For example, Ad2 expressed his view as follows:

"It is not going to be possible to use indigenous language as an official language. Only in my team here in the office, we have Ibibio, Idoma, Tarok, Nupe, Igala and so many others. So is it possible to begin to use all of them in official communication? Or will you rather choose Nupe and ask me to learn it instead of my own? See, this is not possible. Let us continue with the English please."

The position of the above respondent indicates and reflects linguistic politics which can results in linguistic war if any indigenous language is adopted to play a national language role without proper orientation. This means that the Nigeria's dense multilingualism and multiculturalism constitutes serious challenges to past efforts to select a single viable national language. This is because there is no indigenous language that has wide geographical spread and has been generally accepted by the dense ethnic groups in Nigeria for communication.

\section{Responses from Educators (Teachers)}

When responding to the question on the role of English language, the teachers all agreed that they use English strictly at all levels except when teaching indigenous language subjects such as Hausa, Igbo and Yoruba. They are worried and complained on the lack of interest on the side of the government, lack of teachers' training, unavailability of textbooks and teaching materials, and absence of teaching models and approaches. One of the respondents (Ed7) said:

"We are not happy that we are teaching the pupils in English, but we have no option. The government has no interest in the indigenous languages and that is why they have not put any measure to enforce the use of indigenous languages at the pre-primary and primary levels. Like in this school, there have never a time when we have training or workshop on Nigeria Languages. Also no teaching materials and text book written in Hausa in this school. If I was asked to teach Mathematics in my language or Hausa now, how do I go about it in terms of model and approach? These are the issues..."

Another respondent (Ed4) expressed her dissatisfaction on the attitudes of school proprietors and parents towards the indigenous language. She said:

"... Even though there is law that mandates us to teach the pupils in the language of the immediate environment, the school proprietor would not want to hear that. He frowns at teachers that speak indigenous language among themselves in the school. Parents also do not like their children to learn 
indigenous languages. I have encountered many parents like that in my ten years of teaching career."

The response from Ed4 above shows that the Nigerian elite groups have unhealthy attitudes towards the indigenous language which make it very difficult for the languages to strive.

\section{THE RESULTS}

The results showed that majority $(93.3 \%)$ of the sampled population in all the groups are comfortable with the poly-dimensional role of the English language while $6.7 \%$ are not confortable. Meanwhile $83.3 \%$ of the respondents are aware of the national language policy documents while the 16.7 are not aware.

The highest proportions of respondents that are comfortable with the roles played by English language were public administrators and educators while the $6.7 \%$ of the respondents that are not comfortable were strictly media practitioners. Similarly, $16.7 \%$ of the respondents that are not aware of the national language policy document were public administrators while the higher population that agreed to be aware of the policy document were media practitioners and educators.

This means that even though many of the respondents $83.3 \%$ are aware of the national language policy documents, they are not willing to implement them. The perception of many of them suggests that the policy is just a mere paperwork that has no potency. The $93.3 \%$ of the population that agreed to be comfortable with English language playing many roles to the neglect of the indigenous language faulted the inability of the government to adopt one indigenous language as a national language.

\section{CONCLUSION AND RECOMMENDATION}

The study has attempted to identify and critically discuss the key challenges facing the implementation of Nigeria's current National Language Policy. It has been able to show that the persistent failures and shortcomings observed in the implementation of National Language Policy guidelines and procedures over the five or more decades in Nigeria has given prominence and undeserved recognition to English, a situation which is consequently endangering the indigenous languages in Nigeria. Government should as a matter of priority collaborates with language researchers to produce teaching materials in the indigenous languages. Concerted efforts need to be made by governmental agencies to identify and possibly apply sanctions against all functionaries sand institutions that are responsible for observable failures in the processes and procedures for the sustainable implementation of the language policy and its associated guidelines. The various arms of the mass media also have significant roles to play in popularising the virtues of actively patronizing Nigerian languages through their widespread and consistent usage in as many sociocultural domains as possible. In this regard, national orientation programmes and activities on the sociocultural relevance and educational significance of indigenous languages should be given widespread attention. If all these measures are put in place, as many Nigerian indigenous languages as possible will hopefully begin to flourish, for the overall benefit of national development efforts in the country in the increasingly competitively global environment today.

\section{REFERENCES}


Abioye, T. (2010). Perception of undergraduate newspaper readers on the role of the media in literacy development". Marang Journal of Language \& Literature 20: 97-107.

Ajepe, I. \& Ademowo A.J. (2016). English language dominance and the fate of indigenous languages in Nigeria. International Journal of History and Cultural Studies (IJHCS), Vol. 2, No. 4, pp. 10-17

Akindele, F. \& Adegbite W. (2005). The Sociology and politics of English in Nigeria. Obafemi Awolowo University Press, Ile-Ife

Ayakoroma, B. F. (2017). Reviving the use of indigenous languages in the contemporary Nigerian society: The National Institute for Cultural Orientation (NICO) initiative. International Journal of Language and Linguistics, Vol.4, No. 4, pp. 182-188

Belkbir, R. (2019). Investigating the Impact of English for Specific Purposes (ESP) Curriculum on Moroccan Graduates' Career. International Journal of Language and Literary Studies, 1(1), 64-71. https://doi.org/10.36892/ijlls.v1i1.26

Danladi, S. S. (2013). Language policy: Nigeria and the role of English language in the 21st century. European Scientific Journal, Vol. 9, No.17, pp. 1-21

Dorgu, T. E. \& Igbojinwaekwu, P. C. (2016). Comparative effects of using Igbo and English languages as media of instructions on academic achievement of pupils in primary school Mathematics. International Journal of Education, Learning and Development, Vol.4, No.2, pp. 80-97

Ibrahim, J. and Gwandu, S. A. (2016). Language policy on education in Nigeria: challenges of multilingual education and future of English language. American Research Journal of English and Literature. Vol. 2, No. 1, pp. 1-10

Igbojinwaekwu, P.C. \& Nneji, N.L. (2012). Restructured Mathematics questions and academic achievement of students in senior school Mathematics. African Indices, British University in Egypt (BUE), Etsharonk City, Cairo. Vol. 4, No. 1, pp. 14-23.

Ogunmodimu, M. (2015). Language policy in Nigeria: Problems, prospects and perspectives. International Journal of Humanities and Social Science. Vol. 5, No. 9, pp. 154-160

Oluga, S. O., Adewusi, C. O., Babalola, H.A.L., and Oyediran, A. O.(2002). Essentials of use of English: A pragmatic approach. Ede: BOA Educational Publishers

Oluga, S. O. \& Babalola, H. A. L. (2012). Official use of English and the resultant marginalisation of indigenous African languages: The cases of the three major Nigerian languages. European Journal of Social Sciences, Vol.32, No.4, pp. 619631

Oluwole, S. O. (2003). Language planning in a multi-ethnic state: the majority/minority Dichotomy in Nigeria. Nordic Journal of African Studies, Vol. 12, No. 1, pp. 105117

Romaine, S. (2003). Variation in Language and Gender. Blackwell Publishing Ltd, UK

Salisu, A. M. \& Dollah, H. (2015) Language planning and policy in Nigeria: The prospects of Arabic language. Journal of Education and Social Sciences, Vol. 1, No 1, pp. 123-129 


\section{AUTHORS'BIOS}

Francis Abah Owojecho lectures at the Institute of Education, University of Abuja. He has a Master Degree from the University of Jos, Nigeria. Francis was an Editorial Manager managing twelve academic journals at Adonis and Abbey Publishers. His research interests include Sociolinguistics, Morphosyntax, Syntax and Semantics. 